same solution or that of permanganate of potash should be drawn up frequently through the nostrils, so as thoroughly to cleanse them. When the patient cannot swallow, nutrient enemata should be given four times a day; not too frequently if they are to be retained. For this, nothing is better than Dr. Munk's mixture, a tumblerful of milk gruel, a newlaid egg, a tablespoonful of brandy. By following this plan a boy under the joint care of my partner, Dr. C. Kingsford, and myself, twenty years ago, recovered, although he swallowed nothing for sixteen days, and severe paralysis, or rather paresis, ensued. He is now a fine, strong man.

Possibly the adverse effect of depletory treatment has tended to deter from the administration of an aperient ; but in this, as in many other instances, debility is a bugbear. In one severe case I had to give three doses of calomel and jalapin, and follow each dose with a black draught, and even then it was necessary to add one ounce of castor oil. The relief was as marked as the amount of aperients required to obtain it. The nourishment, stimulants, and tonics given subsequently seemed to be all the more thankfully received and gratefully recorded.

The tendency to rheumatism after even a slight attack of diphtheria should never be lost sight of. Possibly this is due to excess of fibrin in the blood; but of the fact I have certain experience.

Five Houses, Clapton, Middlesex.

\section{'THE TREATMENT OF POTT'S DISEASE OF THE SPINE.}

BY THOMAS JAMES WALKER, M.D. LOND., SURGEON TO THE PETERBOROUGH INFIRMARY.

IN a communication on the treatment of Pott's disease of the spine by a gutta-percha jacket, applied in the recumbent posture, published in THE LANCET of July 7th, 1877, I suggested the possibility of applying a casing of gum and chalk on a many-tailed bandage. The suggestion of this material requires correction, as gum and chalk, taking many bours to set, is not adapted for such a purpose. Since writing that communication I have, however, proved by experience, and have on several occasions demonstrated to large numbers of my medical brethren, the facility with which, on the principle then proposed, a plaster-of-Paris jacket may be applied in the recumbent posture, giving all the advantages of Sayre's method, and avoiding the serious daingers and inconveniences of suspension. I have devised the little apparatus here figured (Fig. 1) for charging the

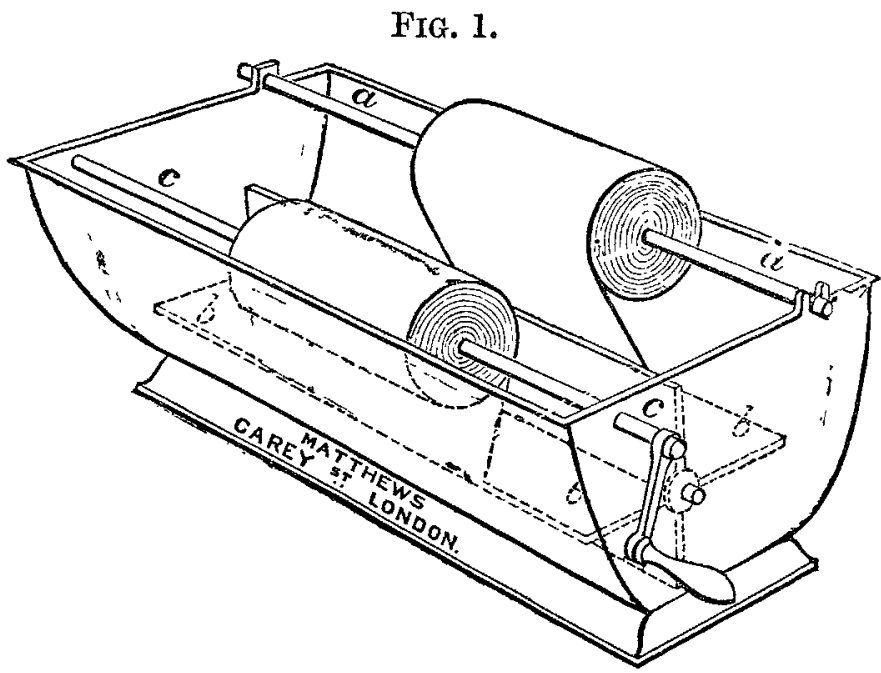

bandage with plaster. The trough is filled with plaster-ofParis mixed with water, to which gum has been added, to retard the setting long enough to admit of the necessary manipulation. For a full-grown child, five pounds of plaster-of-Paris, forty ounces of water, and five ounces of mucilage (B.P.), are about the quantities required, and whatever may be the quantities, these are the proportions in which the materials should be used. About forty yards of Victoria lawn bandage will be required. Three bandages, each nine or ten yards long, may be placed at the same time on the spindle, $a, a$. The ends are carried through the plaster under the fan roller, $b, b, b$, to the spindle, $c$, $c$, on to which the bandages are wound, causing the roller to turn, stirring the plaster, and splashing it over the bandages, so that they become thickly charged. A bandage thus charged is removed from the machine by withdrawing the spindle, $c, c$. It is laid out in slips cut to a suitable length on the bed; each slip overlapping the one below it two-thirds of its width. When a sufficient number of such slips have been laid down to form a jacket reaching from the hips to the axillæ of the patient, another similar layer is laid on the top of it; and for a very strong jacket a third stratum may be superimposed. The patient, clothed in a close-fitting knitted or merino shirt, lies down on the slips, which are then folded over the front of the body, seriatim, as usual with a many-tailed bandage-first the layer last laid down, the last slip to be folded over being, of course, the first laid on the bed. In consequence of the addition of gum, ample time is afforded for these manipulations before the jacket becomes hard. There is time to turn up the edges, to cut and turn over a portion under the axilla, and in other ways to adapt the shell to the requirements of the case. The slips may be laid so as to modify the form of the jacket to an extent which is not possible when the bandage is wound round the patient.

This figure (Fig. 2) is from a photograph of S. W-, aged

FIG. 2.

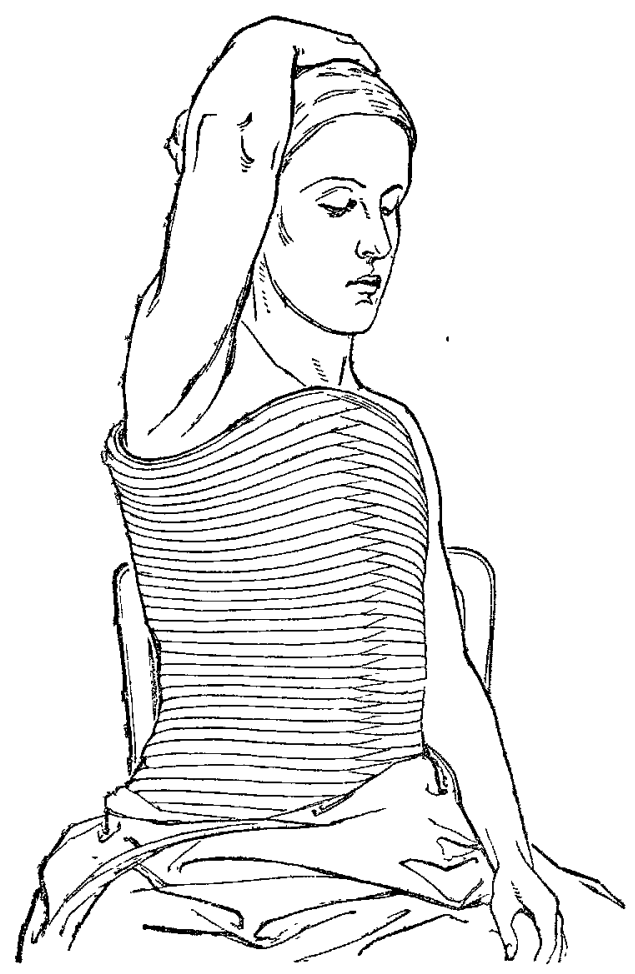

twenty, the subject of angular curvature, the fifth dorsal being the most prominent vertebra. The jacket was applied as I have described, and the ends of the slips crossing over and being brought as high as the top of the sternum, the jacket is of double thickness down the front, thus giving a strong anterior splint, reaching the whole length of the trunk as high as the top of the sternum, and making it absolutely impossible for further bowing of the dorsal spine. No pads were used over either abdomen or breasts in the application of this shell, nor do I ever find them necessary; and the patient, who has worn the casing for two months, tells me that she is comfortable, and that she is not conscious of wearing any apparatus except from her inability to bend her back in stooping.

The illustration shows the special applicability of my method of making the rigid shell to cases in which the curvature is situated high up in the spine. Where the disease is seated in the cervical vertebræ the jacket may be applied in the same manner, two iron eyes being fixed in front in the middle line, into which is slipped the leg of a $\boldsymbol{Y}$-shaped splint, the upper arms of which, directed up on either side of the neck, are perforated at their extremities so as to allow an elastic band to be stretched across. On this the chin rests so as to carry the weight of the head, taking the place of the hands of the patient, which are so con- 
stantly used to support the chin, and prevent the head from falling forward. Or, if preferred, the jurymast apparatus recommended by Sayre may be adopted as readily as when the patient is suspended during the application of the bandage. I believe that if I was somewhat singular when, eighteen months since, $I$ advocated and practised the use of the rigid casing, without suspension, I shall now be supported by the majority of English surgeons in the opinion that suspension of the patient is a part of Sayre's method which it is desirable to avoid, and that the application of the jacket in the manner demonstrated by me in August last at Bath, and on other occasions, is infinitely preferable, securing as it does, without risk to the patient or inconvenience to the surgeon, the fixing of the diseased bones in the most favourable position for obtaining a cure with a minimum of deformity.

\section{BOARD AND DENOMINATIONAL SCHOOLS AS CENTRES OF FEVER POISON.}

\section{BY HARRY D'OYLEY FOOTE, M.D.,}

SENIOR SURGEON TO THE ROTHERHAM PUBLIC HOSPITAL, ETC.

DURING a lengthened and somewhat disastrous epidemic, both rural and urban, I have been struck with the serious conditions emanating from our board and denominational schools, for the wide spreading of the contagium, more particularly of scarlet fever; and, as a result, the marked fatality amongst children attending, and those coming more immediately in contact with them, as the members of the same family. By a compulsory system, parents are urged to send their children to school, often I am aware from infected districts, and very often from houses where brothers and sisters are ill. Thus parents in some cases have a desire avowedly to free themselves of those children apparently healthy, thinking by these means to escape the disease; many, no doubt with the knowledge of previous pressure brought to bear upon them, wishful to carry out the letter of the law; some from a wholesome fear of the attendance officers. But others ignorantly send them with the rash out upon them, and in every stage of peeling, careless of the risk, and heedless of the results. I have constantly cases coming under my observation in which $I$ detect reasons portrayed in the above category.

In this way we have to combat a most serious and growing evil in our midst--children congregated together in large numbers from every part of a district. These schools, fulfilling the conditions of the Elementary Education Act it must be admitted, bring together a miscellaneous class of children, the residuum of society. In the majority of cases their clothing is of an indifferent character-mere rags, descended from other people's cast off, probably sold from fever foci, discarded perhaps from infected houses in other removes of the social scale, ultimately gravitating to the lowest grades, and forming the scanty coverings of these nomadic people and their children - the true contagium carriers. Hence we never seem to be free from scarlet fever. Formerly we had periods of repose of some duration-not so now; we never seem to be rid of the pest, as new sources of contagia are continually springing up and being regularly imported into our schools, from whence it again radiates to the most remote parts of the district, which, whether rural or urban, and however thinly populated, fare no better than others. No doubt there are other well-known sources, such as hospital out-patient waiting-rooms, workhouse hospital and relieving officers' waiting-rooms, and others forming their centres; but these cannot compare with the extra. ordinary conditions which ever surround the system of schools fulfilling the new elementary code. It seems specially created to disseminate fever far and near. The young are here brought together at an age when they are most prone to take fever, concentrated in rooms teeming with exhalations from without and within, the area in many cases totally insufficient for the accommodation given, ventilation not always of the most scientific kind, often inadequately performed, and masters sometimes indisposed to use the means provided. The atmosphere in these crowded schools is, I fear, too often a hot-bed of fever.
No wonder, then, at the rarages of scarlet fever in families, where one, two, and three are swept off in a few days or weeks, - whole families and districts stricken down by the accumulated poison engendered in these schools, and spread broadcast through the whole parish, its ramifications reach. ing every house, whether rich or poor. If, as very often has occurred, through the interference of the medical officer of health for the district, the schools have been closed, it will always be found that this measure, however important, comes too late; as the whole parish or district has been poisoned beforehand.

The evil must increase if some steps of a legislative character are not taken to avoid it. A systematic medical inspection seems imperatively demanded,-desirable as a factor of the highest importance to stem the ravages of fever. If recognised in other branches of legislative acts for the people, it is equally a necessity here-nay, even more necessary, as it affects those who form the very sinew and muscle of the nation. Every house and child should be submitted to inspection-a principle which admits a wide application, but must suggest itself as of paramount importance to every educated mind.

Children should not return to school without being armed with a medical certificate, or clean bill of health, that they and also their houses are clear of the infection, the latter having been disinfected by a proper authority. School. masters ought not to take upon themselves the onus of taking children back on the word of parents, without some guarantee from a medical authority, as is too often done prematurely, doing irreparable mischief to others. The object of the schoolmaster at present is to get his scholars back again as quickly as possible; he wants his fees, and this incentive is all-powerful. He sends a list of absentees to the clerk of the School Board, who directs the officers to visit them. The attendance officer will seek them up, and if he finds them out of doors, this, in his eyes, will be ample evidence of restoration to health. Grants are also received by schoolmasters, one particularly for attendance, and if any child fails in the average prescribed he loses the grant. Pecuniary matters, it will be seen, have a great deal to do with the spread of fever, as the emoluments of masters are based on such a scale as to make them look rigidly after their fees. If children stop at home their fees are stopped likewise, so that it is a very serious matter to some rural masters, when to shut up the school is beggary staring them in the face, besides loss of grants. Here, then, are a variety of causes all tending to hurry the children to school, too often in a weak state of health, perhaps but partially convalescent from exanthemata, producing the most disastrous results.

There seems to be a void in the Elementary Education Act, not grappled with by the promoters, perhaps unintentionally omitted; if intentionally, a very grave omission which calls for immediate action, as it is fraught with the utmost importance to the vital statistics of this country, and which has cost hecatombs of lives already that might have been spared. Health officers throughout the kingdom are becoming alive to the gravity of the question, and cannot fail to see the mischievous conditions emanating from these centres of fever poison. Not to provide for the medical inspection and supervision of a class of children accepted as the worst, and thereby requiring compulsory laws-notoriously the black spot in the public weal of our constitutionis, to my mind, an oversight of the framers, incompatible with their position, and difficult to understand, exhibiting the great need of a Minister of Health. Every point of law, as far as compulsion is concerned, has been strained to the utmost to bring these children under the leash, often bearing heavily on parents and widows, but certainly on a magnificent scale of expenditure to the ratepayer, besides at a vast cost to the whole country. Yet the experts and framers of this Act of progress entirely ignored the vital status of these children, nor considered how entirely the health of a community is ruled by the congregation of such large numbers of children together without any medical supervision.

Rotherham.

JerVIS-STREET HosPITAL, DUBLIN.-A meoting was held last week in Dublin for the purpose of raising funds to rebuild this institution. The sum of $£ 35,000$ will be required during the next five years, of which $f 1000$ has been already promised. 